\title{
Exploratory Mapping Research on Crowdfunding
}

\author{
Yud Buana \\ BINUS Entrepreneurship Centre, Management Department, Bina Nusantara University \\ Jln. Kebon Jeruk Raya No. 27, Jakarta Barat 11530, Indonesia, \\ yud.buana@binus.ac.id
}

Received: $4^{\text {th }}$ September 2017/ Revised: 30 $0^{\text {th }}$ November 2017/ Accepted: $7^{\text {th }}$ December 2017

How to Cite: Buana, Y. (2018). Exploratory Mapping Research on Crowdfunding. Binus Business Review, 9(1), 55-61. https://doi.org/10.21512/bbr.v9i1.3955

\begin{abstract}
The research aimed to provide a systematic literature review of the available research evidence on crowdfunding. Tenets of keyword search and fit analysis were used to review the term of crowdfunding. It was used to reveal the ambiguity and variations in the literature, and to create a mapping for further research. This research explored and tried to form a corridor for crowdfunding according to business models, intermediary platforms, the planned strategy, the emergence of risks and decisions, regulation and governance, the value creation, and other things such as humanitarian and other non-financial matter. The result shows that research in the business models of crowdfunding platform and successful strategy is the preferred topics. Then, it mostly comes from European and North America according to the number of publications.
\end{abstract}

Keywords: crowdfunding, literature review

\section{INTRODUCTION}

Crowdfunding provides methods for entrepreneurs to finance their projects (Mitra, 2012). The way it works is similar to raise small amounts of money. It tends to be gathered as many people as possible (Schwienbacher \& Larralde, 2010), through non-equity arrangements (Bradford, 2012), a social media networking platform (Lu et al., 2014), and in an internet-based (Bradford, 2012). It enables funders to communicate with each other as well as with fundraisers (Hemer, 2011). However, there is few scientific literature that explains when the first term of crowdfunding is implemented (Mollick, 2014), as well as its history (Freedman \& Nutting, 2014). This is due to the similarity of action with the fundraising (Schwienbacher \& Larralde, 2010). Therefore, along with the development of Internet technology, it elicits boundless social interaction through electronic media. The Internet community (Hemer, 2011) is used by the activity of crowdfunding itself (Agrawal, Catalini, \& Goldfarb, 2014). Then, this research uses the term of crowdfunding to be associated with the electronic transactions involved in it (Bradford, 2012).
According to Schwienbacher and Larralde (2010), the business model of crowdfunding is divided into equity-based, royalty-based, lending-based, reward-based, and donation-based. Other researchers divide it into pledge threshold model, micro-lending model, investment or equity models, holding model, and the club model (Hemer, 2011). Meanwhile, based on the actors involved and their purposes are divided into crowdfounders with their goals of the crowdfunding effort, and crowdfunders with their goals of the investment (Mollick, 2014). There is another term that is backers or contributors. They are more or less the same meaning as the donors. This is due to the more social-focused crowdfunding model. There is no promise or obligation from the fundraiser to refund the funds, except the obligation to complete the project. In the equity crowdfunding model as well as pledge-based crowdfunding, the term of crowdfunders or investors seems to be preferred. It is because the models tend to be investing. Meanwhile, the term for the initiate is people who initiate or conduct crowdfunding activities. It is commonly encountered as an entrepreneur, fund-raiser, or crowdfounder. The intermediaries that function are 
important terms of crowdfunding enable process of bridging two parties (Agrawal, Catalini, \& Goldfarb, 2014). It is between crowdfounders and crowdfunders in creating the formulation that unites business models and multiple platforms to a strategy for the success of the entrepreneurial project. Judging from the processes occurring within the intermediaries, crowdfunding creates a two-sided market (Tomczak \& Brem, 2013). Thus, the increase in value creation competition within and between both side of participants also raises risks in the reciprocal direction (Agrawal, Catalini, \& Goldfarb, 2014).

An increased risk also applies to crowdfunding platforms. It plays a major role as an intermediary (Belleflamme, Omrani, \& Peitz, 2015). The increasing role of intermediaries means opening up new business opportunities, namely the intermediary business that facilitates fundraising through crowdfunding. As it has been before, opportunity in every new business is always attractive for the competition. It usually hopes of more participation which will make it more attractive to develop crowdfunding activities in worldwide.

Recently crowdfunding has been widely decided by the crowdfounders to be used as a source of fund for entrepreneurial projects (Belleflamme, Lambert, \& Schweinbacher, 2014). Consistent with that, the research and development on the model and platform of crowdfunding bring up the option for crowdfunders. For example, it is about their decision to use crowdfunding as a vehicle investment (Tomczak \& Brem, 2013). Throughout the existing research and the exception of the donation-based model, the other business models will offer feedback in the physical form to funders exclusively (Belleflamme, Lambert, \& Schwienbacher, 2013). Feedback varies ranging from simple as the reward-based models, to the sophisticated investment model such as equitybased models. Therefore, in the model of equity-based crowdfunding, the risk from a financial standpoint is the most important thing (Harrison, 2013). Many researches conducted on the regulation and governance can be applied to those models of crowdfunding platforms (Cumming \& Johan, 2013).

According to the process, equity-based crowdfunding requires a great deal of layers that contain many agreements (Ahlers et al., 2015). Those agreements should be based on binding laws and regulations (Bradford, 2012). Equitybased crowdfunding is a form of financing where entrepreneurs make fundraisings like an open call to the public to sell some equity or bond-shaped shares (Ahlers et al., 2015). However, this time, the process is done using the Internet or with electronic transactions online (Bradford, 2012). With the open call and investment process done on the online platform, it is expected to attract many investors (Schwienbacher \& Larralde, 2010). In equity-based crowdfunding, the funder acts as an investor or lender (Agrawal, Catalini, \& Goldfarb, 2014). They must have the ability to assess the investment risk (Wilson \& Testoni, 2014). The performance expects the successful campaign (Moleskis \& Canela, 2016). The uncertainty from the funder's perspective is whether the project will generate profits from the sold product or service or not. In other words, the end result will suit the appetites of prospective customers. So, the expectation of big income occurs potentially when crowdfounders can relate well with prospective funders (Moritz, Block, \& Lutz, 2015). At equity-based crowdfunding, entrepreneurs have ownership rights to fund a campaign (Belleflamme, Omrani, \& Peitz, 2015). Moreover, equity-based crowdfunding has the same terms with crowdinvesting (Wilson \& Testoni, 2014). It is a form of financing where entrepreneurs request funds on the Internet to attract some investors.

Royalty-based crowdfunding offers only a fraction of the revenue or profits that will be generated (Agrawal, Catalini, \& Goldfarb, 2014). This type of crowdfunding usually determines the targets to be achieved (Schwienbacher \& Larralde, 2010). This "all-or-nothing" approach means that if a project does not reach its target, it does not receive the promised money (Mitra, 2012). This is considered as a way to protect funders (Bradford, 2012). This royalty-based crowdfunding will encourage the entrepreneur to set realistic funding targets that match the amount of money. They need to realize their project goals (Beaulieu \& Sarker, 2015). The model of royaltybased crowdfunding is when the backers receive a royalty interest originating from intellectual property registered by the entrepreneur. Another model is in the form of backers receives a contract that guarantees a fixed percentage or fixed income from the royalties of interest on its property (Safner, 2014). For the time being, this model is less common but is gaining attention with the emergence of newer innovations (Mollick, 2014).

In the lending-based crowdfunding model, entrepreneurs will borrow money from a group of people (Morse, 2015). This loan is unlike a bank (De Buysere et al., 2012). This model uses the usual intermediary of a platform, where the platform will also act to make payments to creditors. Other platforms also act as matches, in which borrowers and lenders will connect in a closed deal (Belleflamme, Omrani, \& Peitz, 2015).

For a social project, some other intermediary that may also act as a platform gives the option to provide interest-free loans (De Buysere et al., 2012). For example, it occurs in developing countries such as the existence of microfinance without interest paid to the lender (Beaulieu \& Sarker, 2015). This lendingbased crowdfunding model has its basic concept. It is not an exciting new model of financing. This model is based on ordinary peer-to-peer lending (Bradford, 2012). However, it is developed in such way to avoid the possibility of action that is not based on good intentions. Therefore, one of the characteristics is that creditors and borrowers usually do not know each other (Belleflamme, Omrani, \& Peitz, 2015). In this peer-to-peer loan model, the primary motivation of the funder is a higher financial return, in which the risk 
factors have taken into account (Morse, 2015). Thus, those calculations are done by a special platform or an independent agency (De Buysere et al., 2012). In this crowdfunding model, only money provided by the funder may be lent. Therefore, there is no concept of money creation in this platform which is not the case as in traditional banks. As a result, systemic risk as much as possible can be avoided (Belleflamme, Omrani, \& Peitz, 2015).

Then, reward-based crowdfunding is usually used by project owners who want to collect donations for a particular project and can provide small (nonfinancial) rewards (Beaulieu \& Sarker, 2015). Unlike previous crowdfunding models, in this model, the backers play their role as prosumers (De Buysere et al., 2012). The funder is not very interested in financial returns. Instead, the reward is more a symbolic value and the rewards that will be provided by the entrepreneur. It is usually worth much less than the amount of the donation to ensure there is enough money left for the project (Mitra, 2012). Nevertheless, the perception of value can be much higher. In this context, rewards are not necessarily understood as revenue, so the parties do not regard them as legally binding obligations to provide goods, nor do classify them as sales (Bradford, 2012). In this reward-based crowdfunding model, entrepreneurs can attract the attention of the backers through intermediaries or platforms that essentially can repurchase the products (Belleflamme, Omrani, \& Peitz, 2015). The role is to reduce the risk of loss from the entrepreneur's point of view and to reduce the uncertainty of satisfaction output from a backer's point of view (Frydrych et al., 2014). There is an opinion that this rewardbased crowdfunding model, allows backers to be an ambassador of a campaigned product like with the help of social media (De Buysere et al., 2012).

Next, donation-based crowdfunding is different from those mentioned models of pledge-based crowdfunding (Schwienbacher \& Larralde, 2010). The delivery or the success of the crowdfunding objectives becomes an important potential factor for the funder (Belleflamme, Lambert, \& Schwienbacher, 2013). The asymmetry of information surrounds the ability of crowdfounders to payback or even generate future cash flows (Schwienbacher \& Larralde, 2010). This is considered unimportant in the context of donationbased crowdfunding. This crowdfunding model is more similar to traditional fundraising, where the prime motivation of backers is social. Therefore, they are more willing to donate higher amount (Beaulieu \& Sarker, 2015). This type of backers also tends to be more loyal in the long run when the crowdfounders keep on updating the progress of the project (Lehner \& Nicholls, 2014). The campaigning of donation-based crowdfunding relies on voluntary contributions to the public interest (Belleflamme, Omrani, \& Peitz, 2015). Thus, the crowdfounders do not return the money or make any form of repayment, other than obligation to succeed the project in achieving its objectives and recognition in the community (Mitra, 2012).

\section{METHODS}

Systematic literature is selected as a method for identifying and reviewing how crowdfunding has been studied previously. The research is conducted systematically. It is to summarize existing research articles through review and analyze the process of the searching result of the literature (Thuan, Antunes, \& Johnstone, 2016). This research uses several online research databases such as IDEAS (bibliographic database, see https://ideas.repec.org/) as part of Research Papers in Economic (RePEc), ProQuest, Springer Link, Science Direct, and Taylor and Francis.

Those are selected due to having a large coverage in many countries and representing the journal articles, working papers, and conference proceedings in the business, management, accounting, economics, econometrics, and finance. Furthermore, those databases have a metadata service that helps to gather articles. Thus, it can improve the reliability of the results and verify the scientific article. However, the articles of this research are limited until 2016 in the year of publication, and those are in open accessed status.

In this research, the term of crowdfunding is formulated to be the main search term with the definitive argument. It refers to the gathering only in the form about amount of money from large number of individuals via the Internet. Therefore, the terms of crowdsourcing and fundraising are excluded from the searching process. Other terms are used to support the search to focus more on the topic and the discussion topic. Thus, it facilitates the process of clustering. Those supporting terms used are in accordance with the research question and combined with the main term to search it with keywords.

Then, combining the search keyword is applied by using the operating codes. It is adjusted in accordance with the rules of the online research databases such as $(+)$ or AND and $(\mid)$ or OR. Furthermore, the results are reviewed and analyzed manually through the title and abstract for selection process of the topics that are closely related to the keywords used. It also includes selecting the topic similarity between one to another. If similarities are founded, the more profound analysis will be done regarding the uniqueness of the existing articles. Figure 1 shows the strategy for systematic literature review.

The development of crowdfunding research leads to the questions about the direction and interests of the crowdfunding research. This raises questions about how to map crowdfunding research from the viewpoint of intermediary. It looks up at the two sides of the market by covering business models, risk, regulation, valuation, and non-financial factors that support it. Therefore, all 87 articles are conducted in a manual review and analysis into four major sections according to financial perspective. First, the business models of crowdfunding platforms and strategies make it successful. The second, it manages the risks with the right decision. Meanwhile, the 
regulations that should be applied in achieving good governance and financial value creation for both sides beneficiaries, the crowdfounder and the crowdfunder, are in the third and fourth sections. In the meantime, it is from the perspective of non-financial in supporting the mentioned four parts is placed on the fifth.

In consideration of research question, the keyword search can be formulated as follows: crowdfunding, business models, platforms, strategy, success determination, financial risks, decisions, laws, regulations, governance, and valuation. Meanwhile, the selected measurement indicators are based on data related to the publication of research conducted such as year of publication, country origin of author (it is grouped by region due to scattered location), document type, and a number of citations.

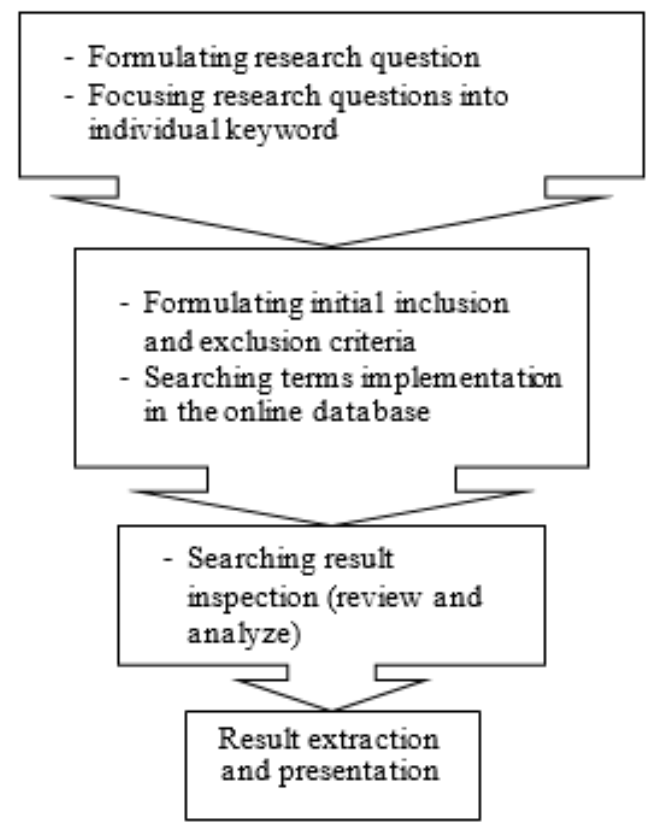

Figure 1 Strategy for Systematic Literature Review

\section{RESULTS AND DISCUSSIONS}

The searching starts in the early week of January 2017. Due to the limitation of the publication that is up to 2016 , the results are 2.724 articles. The first stage filtration has resulted in 2.035 articles to be discarded due to duplication, closed accessed, and unusing English as the language of writing. The remaining 689 articles are manually recorded and evaluated. Then, 602 articles are taken out because it has term of crowdfunding in the body writing, but it is not as the main discussion topics or subjects. After thoroughly analyzing the remaining 87 articles, the first extraction is presented in Table 1 .

After extraction, the next process is clustering and synthesizing in accordance with the results of the earlier use of operation code. The purpose of clustering the extracted data is mainly for a helicopter view so that the entire data can be accommodated accordingly. In addition to being more specific, clustering author's country of origin in accordance with the geographical region of the country tends to be influential matter as distance-sensitive costs in the future (Agrawal, Catalini, \& Goldfarb, 2011). Until 2010, there is only one article, but in subsequent years, it shows the growing number of publications.

Table 1 Years of Publication, Country Region of Author, Number of Publication, and Citation

\begin{tabular}{llcc}
\hline Year & $\begin{array}{c}\text { Country Region of } \\
\text { Author }\end{array}$ & $\begin{array}{c}\text { Number } \\
\text { of Publication }\end{array}$ & $\begin{array}{c}\text { Number } \\
\text { of cites }\end{array}$ \\
\hline$\leq 2010$ & Europe & 1 & 506 \\
2011 & Europe & 1 & 236 \\
& North America & 2 & 506 \\
2012 & - & - & - \\
2013 & Europe & 5 & 479 \\
& North America & 2 & 371 \\
2014 & Europe & 23 & 1280 \\
& North America & 3 & 999 \\
2015 & Europe & 15 & 118 \\
& North America & 9 & 273 \\
& Asia Pacific & 1 & 0 \\
2016 & Europe & 13 & 65 \\
& North America & 8 & 212 \\
& Asia Pacific & 3 & 23 \\
& South America & 1 & 9 \\
\hline
\end{tabular}

Table 2 Number of Publication According to the Research Topic and Country Region of Author

\begin{tabular}{lcccc}
\hline Research topic & 22 & 7 & 1 & - \\
$\begin{array}{l}\text { Model, platforms and } \\
\text { strategy }\end{array}$ & 15 & 4 & 1 & - \\
$\begin{array}{l}\text { Risk and decision } \\
\begin{array}{l}\text { Law, regulatory and } \\
\text { governance }\end{array}\end{array}$ & 10 & 17 & 1 & 1 \\
Valuation & 4 & 3 & 1 & - \\
\hline
\end{tabular}

The clustering the extracted data is for research topics as presented in Table 2. This aims to understand the trends of the problems and interests that arise. According to Table 2, researchers from the European continent conduct more research on crowdfunding. Those are the main topic of business models, crowdfunding platforms, and strategy on how to achieve success for it. This is reasonable because, 
from the total 87 analyzed articles, 58 articles or $66,67 \%$ are from Europe. The business model provided by the platform is the most important thing from crowdfunding. For this reason, order placement and the platform business models have priority, along with its important role as well. Meanwhile, regulatory and governance rank the second in interest in continental Europe. However, it ranks top in North America. Crowdfunding can involve Internet users around the world so that the necessary regulations can mitigate any risks that may arise.

Table 3 Percentage of Research Design Approach According to Research Topic

\begin{tabular}{lccc}
\hline \multicolumn{1}{c}{ Research topic } & Quantitative & Qualitative & $\begin{array}{c}\text { Mixed } \\
\text { methods }\end{array}$ \\
\hline $\begin{array}{l}\text { Model, platforms } \\
\text { and strategy }\end{array}$ & 10 & 1 & 19 \\
$\begin{array}{l}\text { Risk and decision } \\
\text { Law, regulatory and } \\
\text { governance }\end{array}$ & 3 & 1 & 16 \\
Valuation & 15 & 3 & 11 \\
\hline
\end{tabular}

It aims to determine the pattern of research design approaches. In Table 3, 47 articles or $54 \%$ are using mix method. Considering crowdfunding term is relatively new and the development of Internet and social media, most of the research is exploratory and explanatory.

Table 4 Number of Citation According to the Research Topic and Document Type

\begin{tabular}{lcccc}
\hline Research topic & 2944 & 727 & - & 506 \\
\hline $\begin{array}{l}\text { Model, platforms and } \\
\text { strategy }\end{array}$ & 312 & 6 & - & - \\
$\begin{array}{l}\text { Risk and decision } \\
\text { Law, regulatory and } \\
\text { governance }\end{array}$ & 422 & 63 & 25 & - \\
Valuation & 66 & - & - & - \\
\hline
\end{tabular}

Table 4 illustrates the condition of the existing research status and the development trend of the research topics. Interestingly, this research observes the development of research on crowdfunding through a number of citations. If it is seen from the number of citations on the working papers that have not yet published in the journal, it shows significant interest from researchers on crowdfunding, the business models of the crowdfunding platform, and how to achieve success as its main theme. It is still the same, and the majority comes from Europe and North America as shown in Table 5.

Table 5 Number of Citation According to the Research Topic and Country Region of Author

\begin{tabular}{lcccc}
\hline Research topic & 2292 & 1876 & 9 & - \\
\hline $\begin{array}{l}\text { Model, platforms and } \\
\text { strategy }\end{array}$ & 231 & 85 & 2 & - \\
$\begin{array}{l}\text { Risk and decision } \\
\begin{array}{l}\text { Law, regulatory and } \\
\text { governance }\end{array}\end{array}$ & 155 & 346 & - & 9 \\
Valuation & 6 & 54 & 12 & - \\
\hline
\end{tabular}

In defining crowdfunding, the researcher conducts the approach of financial perspective and non-financial perspective that occurs in the process. Although articles are selected according to the nonfinancial approach, it is still closely linked to financial processes in crowdfunding. The other terms such as crowdsourcing having a broader scope are excluded from the search. However, crowdfunding is part of crowdsourcing (Schwienbacher \& Larralde, 2010). The research also does not use a narrower keyword, such as crowdinvesting. It is because it is part of the crowdfunding term, which is certainly as part of the discussion. All of this is because the precision parameter in using the term is the main reason.

According to Table 1 - Table 5, there are visible patterns formed from clustering the extracted data. It leads to the finding that European region is ranked as the highest number of publications on research of crowdfunding. This also happens with the number of citations. Leaving aside the North American, it becomes interesting when it compares the conditions in Asia Pacific and South America. Even the absence of contributions from African region happens, while their majority is still a developing country. Then, uniqueness is also seen from the interest of the researchers on the business models and strategies of the crowdfunding platform. It tends to be much higher in Europe and North America. Rather than the creation of value, 12 of 23 citations from those articles in Asia Pacific discuss the value creation. The delay in the emergence of research comes from Asia Pacific. It was just beginning to be published in 2015. It is probably because of delay in subsequent studies.

The research does not make a comparison between the number of citations and the number of publications because of the inequality gap. In addition, the other factors are the existence of many publications with very few citations or even zero. In the meantime, there are only a few articles that have hundreds of citations. The older articles tend to have more citations. This is shown in Table 1. 
North American region consists of a few countries than Europe. It can allow it to focus better on the sectors that are considered essential for maintaining stability on the political, social, and economic. Thus, it is quite reasonable that there are many topical researches in laws and regulations regarding this crowdfunding. Meanwhile, in European area, which has not yet entirely unified, has quaint constraint related to the state of political, social, and economic. It is depicted in the regulations of each country and cross-border issues. By examining the view on success stories about crowdfunding, many opinions focus on the strategy about how to make it successful. It is preceded by the making of the business model and the platform, identification of problems that lead to the mitigation of risks, the process of discussion to integrate to the laws, and regulations that exist to the system governance. It can increase value of both sides. The finding framework is in Figure 2.

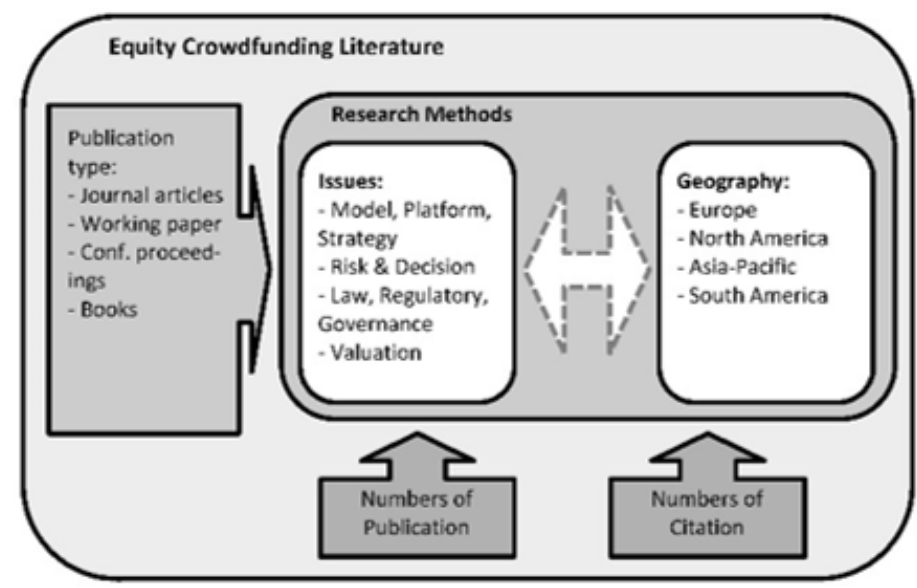

Figure 2 Frameworks of Findings

\section{CONCLUSIONS}

Business models of crowdfunding invite major interest of researchers because its tendency is still flexible to be developed (Belleflamme, Omrani, \& Peitz, 2015). The development of technological sophistication, social dynamics, the condition of individual psychology, and human movement is the main and wide variable to be explored (Vinciarelli et al., 2015). Meanwhile, a strategy to succeed the crowdfunding project has also become very important as it involves so many people from all walks of life. They allow the emergence of new variations that can be developed (Kshetri, 2015).

The business model is closely related to the strategy regarding how to form an optimal and effective platform. Thus, it can be applied to the community (Lehner \& Nicholls, 2014). For that, the best design of a crowdfunding platform will also require a positive commitment from the achievement of the welfare of society, rather than the goal of the entrepreneur. So, crowdfunding design will be preferred if it is built based on the active participation of the community which will be involved as crowdfunders.

However, in the form of social crowdfunding, the business model is the risk that arises. It must be considered and mitigated properly especially in the form of equity crowdfunding (Hornuf \& Schwienbacher, 2016). Looking at this sequential pattern, it will be wise if the risk considerations are incorporated into the crowdfunding planning process. The risks are to be perceived. Then, for the possibility of the emergence of new risks, the development era is very important. About that, this research put the financial aspect forwards, and planning process will be interesting if it involves all perceived financial aspects.

In a variety of perspectives, from the general public to the experts and stakeholders, it will enable the achievement of a proper synergy. All articles reviewed successfully are conical to a particular pattern. It raises the importance of a business model, platform, strategy design, risk management and decision making, regulatory, legal and management aspects, and valuebuilding efforts based on two sides of the market. Those are crowdfounder and crowdfunder.

In addition to requiring analysis to support decision-making on both sides, crowdfounder and crowdfunder, it is for analysis to the formulation of rules and regulations, related laws, and governance in society. There is even the possibility of the crosscountry arrangements worldwide. These conditions make this research point of view toward developing the themes of the creation of value, and non-financial matters. Those are still to provide support to the crowdfunding from a financial perspective.

This research is limited by the term of crowdfunding as the search keyword. This uses only one online research database. Moreover, due to crowdfunding, it is a relatively new research topic. It is very feasible to be developed more widely. Therefore, more innovations from different perspectives of science and thought are needed to enrich the literature on the review of this crowdfunding theme.

\section{REFERENCES}

Agrawal, A. K., Catalini, C., \& Goldfarb, A. (2011). The geography of crowdfunding (No. w16820). National Bureau of Economic Research.

Agrawal, A., Catalini, C., \& Goldfarb, A. (2014). Some simple economics of crowdfunding. Innovation Policy and the Economy, 14(1), 63-97.

Ahlers, G. K., Cumming, D., Günther, C., \& Schweizer, D. (2015). Signaling in equity crowdfunding. Entrepreneurship Theory and Practice, 39(4), 955980.

Beaulieu, T., \& Sarker, S. (2015). A conceptual framework for understanding crowdfunding. CAIS, 37, 1.

Belleflamme, P., Lambert, T., \& Schweinbacher, A. (2014). Crowdfunding: Tapping the right crowd. Journal of Business Venturing, 29(5), 585-609. 
Belleflamme, P., Lambert, T., \& Schwienbacher, A. (2013). Individual crowdfunding practices. Venture Capital, Taylor \& Francis Journals, 15(4), 313-333.

Belleflamme, P., Omrani, N., \& Peitz, M. (2015). The economics of crowdfunding platforms. Information Economics and Policy, 33, 11-28.

Bradford, C. S. (2012). Crowdfunding and the federal securities laws. Columbia Business Law Review, 2012(1), 1 .

Cumming, D., \& Johan, S. (2013). Demand-driven securities regulation: Evidence from crowdfunding. Venture Capital, Taylor \& Francis Journals, 15(4), 361-379.

De Buysere, K., Gajda, O., Kleverlaan, R., Marom, D., \& Klaes, M. (2012). A framework for European crowdfunding. European Crowdfunding Network.

Freedman, D. M., \& Nutting, M. R. (2014). A brief history of crowdfunding including rewards, donation, debt, and equity platforms in the USA. Retrieved from http://www.freedman-chicago.com/ec4i/History-ofCrowdfunding.pdf

Frydrych, D., Bock, A., Kinder, T., \& Koeck, B. (2014, July). Exploring entrepreneurial legitimacy in reward-based crowdfunding. Venture Capital, Taylor \& Francis Journals, 16(3), 247-269.

Harrison, R. (2013). Crowdfunding and the revitalisation of the early stage risk capital market: Catalyst or chimera? Venture Capital, Taylor \& Francis Journals, 15(4), 283-287.

Hemer, J. (2011). A snapshot on crowdfunding, Working papers firms and region, No. R2/2011. Fraunhofer Institute for Systems and Innovation Research (ISI).

Hornuf, L., \& Schwienbacher, A. (2016). Should securities regulation promote equity crowdfunding? Small Business Economics, 49(3), 579-593.

Kshetri, N. (2015). Success of crowd-based online technology in fundraising: An institutional perspective. Journal of International Management, 21(2), 100-116.

Lehner, O., \& Nicholls, A. (2014). Social finance and crowdfunding for social enterprises: A public-private case study providing legitimacy and leverage. Venture Capital, Taylor \& Francis Journals, 16(3), 271-286.
Lu, C. T., Xie, S., Kong, X., \& Yu, P. S. (2014). Inferring the impacts of social media on crowdfunding. In Proceedings of the $7^{\text {th }}$ ACM International Conference on Web search and Data Mining (pp. 573-582). ACM.

Mitra, D. (2012). The role of crowdfunding in entrepreneurial finance. Delhi Business Review, 13(2), 67.

Moleskis, M., \& Canela, M. A. (2016). Crowdfunding success: The case of Kiva.org. In IESE Business School Working Paper No. 1137-E.

Mollick, E. (2014). The dynamics of crowdfunding: An exploratory study. Journal of Business Venturing, Elsevier, 29(1), 1-16.

Moritz, A., Block, J., \& Lutz, E. (2015). Investor communication in equity-based crowdfunding: A qualitative-empirical study. Qualitative Research in Financial Markets, 7(3), 309-342.

Morse, A. (2015). Peer-to-peer crowdfunding: Information and the potential for disruption in consumer lending. Annual Review of Financial Economics, 7(1), 463482.

Safner, R. (2014). Crowdfunding creative goods, crowding out intellectual property? SSRN Electronic Journal, 1-36. https://doi.org/10.2139/ssrn.2499621

Schwienbacher, A., \& Larralde, B. (2010). Crowdfunding of small entrepreneurial ventures. In D. Cumming (Ed.), The Oxford handbook of entrepreneurial finance. New York: Oxford University Press.

Thuan, N. H., Antunes, P., \& Johnstone, D. (2016). Factors influencing the decision to crowdsource: A systematic literature review. Information Systems Frontiers, 18(1), 47-68.

Tomczak, A., \& Brem, A. (2013). A conceptualized investment model of crowdfunding. Venture Capital, Taylor \& Francis Journals, 15(4), 335-359.

Vinciarelli, A., Esposito, A., André, E., Bonin, F., Chetouani, M., Cohn, J. F., ... \& Heylen, D. (2015). Open challenges in modelling, analysis and synthesis of human behaviour in human-human and humanmachine interactions. Cognitive Computation, 7(4), 397-413.

Wilson, K., \& Testoni, M. (2014). Improving the role of equity crowdfunding in Europe's capital markets. Bruegel Policy Contribution. 